\title{
Buyer and Nonbuyer Barriers to Purchasing Local Food
}

\author{
Lingqiao Qi, Adam N. Rabinowitz, Yizao Liu, and \\ Benjamin Campbell
}

\begin{abstract}
Policymakers and value chain members often use a one-size-fits-all strategy to increase local food consumption. Our results indicate this approach may not be effective; local food buyers and nonbuyers have differing barriers to purchasing more or accessing local food. We examine the effect of demographics, health indicators, shopping location, and zip code on those barriers. Prices and availability are barriers for both buyers and nonbuyers. Consumers with higher healthy diet scores are more likely to think about local food availability. Providing specific products is a more viable strategy than creating additional purchasing venues. These results are important, as governments seek to increase local food purchases and enhance local agriculture.
\end{abstract}

Key Words: barriers, buyers, consumer behavior, local food, nonbuyers

Local food is not a new concept within the U.S. food system. As noted by Martinez et al. (2010), nearly 80 percent of respondents surveyed indicated they either occasionally or always purchase produce from growers. Consumers decide to buy locally grown food for many reasons, such as freshness, to support the local community, and for environmental benefits (Seyfang 2006, Darby et al. 2008, Durham, King and Roheim 2009, Hand and Martinez 2010, Onozaka, Nurse and McFadden 2010, Sharp et al. 2011).

However, even with consumers claiming to purchase local foods and touting the benefits, local food is only a small percentage of total agricultural sales within the United States. Low and Vogel (2011) found local food sales (direct-to-consumer and intermediated channels) in 2008 totaled $\$ 4.8$ billion, making up only 1.9 percent of total farm sales; there is continued interest in increasing both consumption and production of "local" products. Federal, state, and local governments have perhaps been the most visible in the local foods movement by shifting policies to increase local consumption. For instance, the 2008 Food, Conservation, and Energy Act (2008 Farm Act)

Lingqiao Qi, Graduate Research Assistant, Department of Agricultural and Resource Economics, University of Connecticut, 1376 Storrs Road, Storrs, CT 06269-4021. Yizao Liu, Assistant Professor, Agricultural Economics, Sociology, and Education, The Pennsylvania State University, Armsby Building, University Park, PA 16802-5600. Benjamin Campbell, Assistant Professor, Agricultural and Applied Economics, University of Georgia, 314A Conner Hall, Athens, GA 30602-7509. Correspondence: Adam N. Rabinowitz, Assistant Professor " Agricultural and Applied Economics, University of Georgia - 2360 Rainwater Road " Tifton, GA 31793 . Email adam.rabinowitz@uga.edu

Agricultural and Resource Economics Review 46/3 (December 2017) 443-463

(C) The Author(s) 2017. This is an Open Access article, distributed under the terms of the Creative

Commons Attribution licence (http://creativecommons.org/licenses/by/4.0/), which permits unrestricted re-use, distribution, and reproduction in any medium, provided the original work is 
defines a "locally or regionally produced agricultural food product" as one that is found less than 400 miles from its origin or within the state in which it is produced. (H.R. 6124 2008). Further, as noted by Onken and Bernard (2010), all states have implemented some type of local promotional activities. Statelevel activities vary from strict regulations to informational materials to promote local products.

One example of a state-level program is in Connecticut; like many other states, legislators have mandated a goal of increasing consumption of food from within the defined geographic boundaries of the state, but Connecticut has legislated that by 2020, 5 percent of total food expenditures must be locally sourced (Governor's Council for Agricultural Development 2011). Warner et al. (2012), noted that local food purchasing in Connecticut accounted for only 2.5 percent of total food expenditures in 2010, with no significant increase through 2013 (Rabinowitz and Riva 2015).

As state governments try to increase consumption of local food, a central tenet is to increase demand. A critical gap in many of these endeavors is to understand the barriers associated with consumers purchasing more local food. Notably, recommendations tend to concentrate on the population as a whole instead of understanding the differences between buyers' barriers and nonbuyers' barriers. This paper attempts to fill this gap; through understanding the barriers to purchasing, policymakers and other interested parties can make more informed decisions on how to increase consumption of local foods.

\section{Literature}

Consumers' motivation for purchasing local food is influenced by many factors. Demographics are an important factor. For instance, studies have shown that high-income consumers are more likely to purchase local, while gender and education have mixed effects on purchasing (Jekanowski, Williams, and Schiek 2000, Brown 2003, Fernández-Ferrín et al. 2016).

In addition to demographic and economic variables, consumer behavior also influences purchasing of goods. Local foods are perceived as being healthier (Sims 2009), so it is important to consider factors related to health. This includes BMI ${ }^{1}$ as well as methods of computing a healthy eating index such as those used by Teratanavat and Hooker (2006) and Verbeke and López (2005). Additionally, a person's aversion to new food has been measured through the computation of a food neophobia score (Pliner and Hobden 1992), indicating the likelihood of purchasing a variety of products.

With respect to barriers to purchasing local food, Conner et al. (2010) identified five barriers for underrepresented populations in visiting farmer's

$1 \mathrm{BMI}=\left[\right.$ weight $(\mathrm{lb}) /$ height $\left.(\text { inch })^{2}\right] \times 703$; Underweight: BMI $<18.5$; Overweight: $25.0 \leq$ BMI $<2$ 29.9; Obese: $\mathrm{BMI} \geq 30.0$. 
markets, notably price, inability to find desired or identifiably local foods, lack of time, and lack of skill to prepare. Further, as noted by Chambers et al. (2007), price and inconvenience were found to be key barriers to local purchasing. Lack of product choices and limited accessibility make local food more difficult for consumers to find satisfactory products (Hardesty 2008). Furthermore, consumers are less likely to purchase sustainable products if they believe these products are less likely to be available (Vermeir and Verbeke 2006). As these studies and others have found, barriers prevent consumers from buying local food in the market. However, few studies go further to explore the barriers facing different consumer groups, such as the buyers and nonbuyers of local foods. The barriers for influencing purchasing decisions of buyers and nonbuyers are most likely not the same; nonbuyers are prevented from entering the market for local food, while buyers already in the market are prevented from purchasing more local food. By understanding the factors influencing the barriers for these two groups, stakeholders interested in increasing the purchase of local food can target marketing activities to overcome these barriers. This provides us with motivation for this paper.

\section{Data}

This study was part of a larger project designed to investigate consumer demand for local and organic products in Connecticut. An online survey was conducted in the fall of 2013 to assess these objectives. Advantages of online surveys are that they are relatively inexpensive, faster to conduct, and generate more accurate information, while potentially allowing for a larger number of surveys to be collected, compared to mailed or faxed surveys (McCullough 1998, Cobanoglu, Warde, and Moreo 2001, Dillman, Smyth, and Christian 2009). However, a potential disadvantage to online surveys is that consumers without internet access are not included in the sample (Bethlehem 2010). If our sample is representative of the population, discussed below, then the potential biases of not including noninternet users should be minimized, and we can feel more comfortable about the results being generalizable to the population as a whole.

Using the panel database from Global Market Insight, Inc. (GMI), potential participants were emailed an invitation to take part in the survey. Those agreeing to take part were directed to a survey link. To participate, respondents had to be 18 years of age or older and a resident of Connecticut. GMI reported the total incidence rate of the survey was 85 percent. A total of 1,820 panelists who clicked the link agreed to participate the survey. The first two questions that potential participants were asked were their age and ZIP code, as these were the two criteria for participation in the survey. Among the 1,820 panelists, 2 panelists reported their ages as under 18, and 412 panelists reported ZIP codes not in Connecticut. Thus, 414 panelists were immediately disqualified from the survey, leaving 1,406 qualified participants. 
Notably, panelists did not know the content of the survey until they started answering questions, so their decision to participate was independent of the survey content. This process is helpful to reduce the occurrences of selfselection among buyers and nonbuyers of local foods. Respondents were asked questions about demographics, purchasing behavior, eating habits, and health (Table 1). ZIP codes were compared to the 2011 American Community Survey and 2010 U.S. Census Bureau estimates, to match a respondent with population density, household income, median age, and percentage of females, Caucasians, and African Americans in their area. ZIP codes were also matched with the number of farmers' markets within each ZIP code area to assess the impact of access to farmer's markets on barriers to purchasing more local food. To calculate BMI, respondents were asked to provide their height and weight, and we categorized them as underweight, normal, overweight, or obese based on their BMI scores.

From the 1,406 qualified participants, there were 51 respondents who did not answer any questions in the survey. Another 219 observations have some missing values in the sample: 41 observations with a missing value for only the income variable, 30 observations with a missing value for some of the food neophobia questions, 56 observations with missing values for some of the healthy diet questions, 1 observation with a missing value of race, and 90 observations with missing values for more than one variable. For respondents who indicated that they buy local food (the buyers group), we kept only the observations without any missing values. While for respondents who indicated they do not buy local food (the nonbuyers group), we imputed the missing values for the observations with only one missing value, and dropped observations with more than one missing value. We also dropped 6 observations from the nonbuyers group because those respondents indicated that they purchase their groceries from farmers' markets, community-supported agriculture (CSA) store, or roadside stand, which is inconsistent with the concept of being a nonbuyer of local foods. Thus, our final sample contained 985 observations in the buyer group, and 167 observations in the nonbuyer group.

To compare our sample with the local population, we compared the basic characteristics of our data with the U.S. Census. As noted in Table 1, our sample tended to be older (sample $=52$ for buyers and 47 for nonbuyers vs. U.S. Census $=40$ ), although the U.S. Census is not directly comparable to our sample, given that the U.S. Census counts respondents under 18 years of age. Our sample does have a higher income for buyers than the average Connecticut resident (sample $=\$ 93,000$ for buyers and $\$ 70,000$ for nonbuyers vs. U.S. Census $=\$ 69,461$ ). Thereby, any generalizations of results to the population as a whole should keep this caveat in mind.

The descriptive statistics and the t-test of the means between buyers and nonbuyers are provided in Table 1 and provide basic profiles of these two types of consumers. Demographic questions consisted of age, gender, race, household income, number of children, and adults in the household. Health 
Table 1. Descriptive Statistics of Variables Used in the Model

\begin{tabular}{|c|c|c|c|c|}
\hline Variables & Sample & Buyers & Nonbuyers & $\begin{array}{l}\text { T-test Significance of the Means } \\
\text { (Buyers vs. Nonbuyers) }\end{array}$ \\
\hline Observations & 1,152 & 985 & 167 & \\
\hline Female & $62 \%$ & $63 \%$ & $57 \%$ & $*$ \\
\hline Age & 51 & 52 & 47 & $* * *$ \\
\hline Household income in $2012(\$ 1,000)$ & 90 & 93 & 70 & $* * *$ \\
\hline Caucasian & $89 \%$ & $90 \%$ & $88 \%$ & \\
\hline \multicolumn{5}{|l|}{ Education } \\
\hline Some college & $27 \%$ & $27 \%$ & $28 \%$ & \\
\hline Bachelor & $32 \%$ & $32 \%$ & $32 \%$ & \\
\hline Master's or higher & $27 \%$ & $28 \%$ & $23 \%$ & $*$ \\
\hline No. of children & 0.45 & 0.45 & 0.47 & \\
\hline No. of adults & 2.10 & 2.10 & 2.10 & \\
\hline Overweight & $37 \%$ & $37 \%$ & $35 \%$ & \\
\hline Obese & $26 \%$ & $25 \%$ & $29 \%$ & \\
\hline Food neophobia index & 3.37 & 3.31 & 3.77 & $* * *$ \\
\hline Healthy-diet habit index & 4.54 & 4.60 & 4.18 & $* * *$ \\
\hline Local expenditure $(\$ 1,000)$ & 1.12 & 1.31 & - & - \\
\hline \multicolumn{5}{|l|}{ Shopping Location (can select multiple locations) } \\
\hline Supermarket/Grocery & $94 \%$ & $95 \%$ & $93 \%$ & \\
\hline Farmer's market & $33 \%$ & $38 \%$ & - & - \\
\hline Roadside stand/Community supported agriculture & $22 \%$ & $26 \%$ & - & - \\
\hline Warehouse clubs & $38 \%$ & $40 \%$ & $29 \%$ & $* * *$ \\
\hline
\end{tabular}


Table 1. Continued

\begin{tabular}{|c|c|c|c|c|}
\hline Variables & Sample & Buyers & Nonbuyers & $\begin{array}{l}\text { T-test Significance of the Means } \\
\text { (Buyers vs. Nonbuyers) }\end{array}$ \\
\hline Ethnic and specialty health grocery store & $15 \%$ & $17 \%$ & $6 \%$ & $* * *$ \\
\hline Discount grocery store & $13 \%$ & $14 \%$ & $8 \%$ & $* *$ \\
\hline Merchandiser & $14 \%$ & $14 \%$ & $16 \%$ & \\
\hline Other & $6 \%$ & $6 \%$ & $5 \%$ & \\
\hline \multicolumn{5}{|l|}{ ZIP Code Characteristics } \\
\hline Population density $(1,000 /$ sq. mile $)$ & 1.91 & 1.84 & 2.33 & $* * *$ \\
\hline Percent female & $51 \%$ & $51 \%$ & $52 \%$ & $*$ \\
\hline Percent Caucasian & $85 \%$ & $85 \%$ & $83 \%$ & $*$ \\
\hline Percent African American & $9 \%$ & $8 \%$ & $9 \%$ & \\
\hline Household income $(2012)(\$ 1,000)$ & 99.90 & 100.83 & 94.45 & $* *$ \\
\hline Median age & 40.71 & 40.87 & 39.77 & $* * *$ \\
\hline No. of farmer's market & 0.64 & 0.63 & 0.70 & \\
\hline
\end{tabular}

Note: ${ }^{*}{ }^{* *},{ }^{* *}$ represent significance at the $0.1,0.05$, and 0.01 levels. 
questions included BMI and dietary habits. There is a larger proportion of female consumers in the buyers group than nonbuyers group. The average household income in the buyers group is higher than the nonbuyers group. There is a higher proportion of people with a master's degree or higher education in the buyers group. Regarding dietary habits, local food buyers have healthier dietary habits and are less reluctant to try new foods, relative to nonbuyers. Purchasing behavior questions revolved around identifying the shopping location where consumers buy local and nonlocal food and the amount of money spent on local food. Consumers from the two groups have significantly different preferences with respect to shopping locations. Finally, most of the ZIP code characteristics are also different between the two groups, indicating a differentiated geographic dispersion between buyers and nonbuyers of local foods.

Participants' perceptions about barriers in local food markets were collected via a multi-response question in the survey, where we asked respondents "What are the barriers to your purchasing more locally produced foods? (Check all that apply)." Respondents were then given a list of eight barriers that are frequent in the literature and/or frequently occur in discussions with producers, policymakers, and other interested parties.

As shown in Table 2, the list of barriers included high prices, quality issues, three different barriers relating to availability, labeling issues, whether they consider local to be a marketing gimmick, and an "other" option for barriers

Table 2. Breakdown of Barriers to Purchasing More Local by Buyers and Nonbuyers

\begin{tabular}{|c|c|c|c|}
\hline Barriers & Buyers & Nonbuyers & $\begin{array}{c}\text { T-test Significance of the } \\
\text { Means }\end{array}$ \\
\hline High prices & $54 \%$ & $60 \%$ & $*$ \\
\hline Availability & $56 \%$ & $30 \%$ & $* * *$ \\
\hline $\begin{array}{l}\text { Lack of products available that I } \\
\text { want }\end{array}$ & $37 \%$ & $14 \%$ & $* * *$ \\
\hline $\begin{array}{l}\text { Shops do not carry local } \\
\text { products }\end{array}$ & $28 \%$ & $17 \%$ & $* * *$ \\
\hline Lack of unique local products & $11 \%$ & $6 \%$ & $* *$ \\
\hline \multicolumn{4}{|l|}{ Labeling } \\
\hline Local not labeled where I shop & $25 \%$ & $28 \%$ & \\
\hline Quality issues & $11 \%$ & $4 \%$ & $* * *$ \\
\hline Other & $10 \%$ & $16 \%$ & $* * *$ \\
\hline $\begin{array}{l}\text { Consider local a marketing } \\
\text { gimmick }\end{array}$ & $3 \%$ & $7 \%$ & $* * *$ \\
\hline
\end{tabular}

Note: ${ }^{*}, * *, * *$ represent significance at the $0.1,0.05$, and 0.01 levels. 
not listed. The barriers relating to availability were defined as: "shops do not carry local products," examining availability of local products; "lack of unique local products," referring to variety; and "lack of products available that I want," focusing on consumers' demands and preferences.

Examining the barriers affecting buyers and nonbuyers of local food, we see notable differences between the two groups (Table 2). We used a t-test to compare differences in the mean number of respondents identifying a specific barrier as a limitation to either purchasing or purchasing more local foods. As one might expect, and consistent with previous literature, price was found to be the biggest barrier to buying more local food, with over half of respondents indicating high prices for local foods as a barrier to increasing their purchases. As for availability, a higher proportion of buyers (56 percent) indicated that availability is an issue relative to nonbuyers (30 percent). When asked whether shops carry local products they want, 37 percent responded this was a barrier to buying more local foods, while only 15 percent of nonbuyers indicated this was a concern. Further supporting concerns were about availability: 28 percent of buyers responded that shops do not carry local products compared to 18 percent of nonbuyers. Respondents felt, to a lesser degree, a lack of unique local products available, with 11 percent of buyers identifying that barrier and only 6 percent of nonbuyers.

While there were more nonbuyers (28 percent) indicating lack of labeling as an issue in purchasing more local food relative to buyers (25 percent), this is not a statistically significant difference. The "local label" provides information to help consumers identify local food. Quality was an issue for 11 percent of the buyers, while only 4 percent of nonbuyers expressed concern about this issue. In the empirical analysis, we removed the quality barrier from the model for the nonbuyers group due to few respondents choosing this option. We also removed the "gimmick" barrier for the same reason. There were 16 percent of nonbuyers and 10 percent of buyers concerned about "other" barriers not listed in the survey. Unfortunately have no further information about the exact nature of the "other" barriers, and thus we also removed this from our empirical analysis.

\section{Empirical Model}

To assess the demographics', purchasing behaviors', health indicators', and ZIP code characteristics' impact on barriers to purchasing local foods, we used a multivariate probit model (MVP), whereby the dependent variables were binary, with 1 being if a respondent marked a barrier as a reason for purchasing less local food and 0 otherwise. Specifically, we consider dependent variables of price, quality, availability (equal to one if a respondent marked at least one of the three barriers including "shops do not carry local products," "lack of products available that I want," and "lack of unique local products," and equal to zero otherwise), and labeling. Edwards 
and Allenby (2003) proposed an MVP model to deal with multiple response data that arise in the study of consumer behavior. One advantage of using an MVP is that it allows for the correlation between alternatives, as opposed to a multivariate logit model (MVL) that assumes alternatives are independent (Aurier and Mejía 2014).

As can be seen in Table 1, many of the characteristics of buyers were significantly different than for nonbuyers; thereby, we analyzed the buyers and nonbuyers in separate models. Furthermore, to model the choice of increasing local food consumption depends on whether one already buys local foods or not. For buyers, we are interested in barriers preventing them from increasing local food consumption, given they are already in the market. For nonbuyers, we are interested in barriers to entering the market for local foods, or increasing their local food consumption from zero.

Assuming the total number of observations is $n$, and $y_{i t}{ }^{*}$ represents the perception of respondent $i$ for barrier $j(j=1,2, \ldots, 4)$. Consumers' perception of barrier $j$ is affected by a set of factors, such as consumer demographics, purchasing behavior including expenditure, and health, in a vector of $\boldsymbol{X}_{i j}$, and a random term $\varepsilon_{\mathrm{ij}}$. Thus, consumers' perceptions of barrier $j$ is written as:

$$
Y_{i j}^{*}=\beta_{j}^{\prime} \mathbf{X}_{i j}+\varepsilon_{i j}
$$

where error term $\varepsilon_{\mathrm{ij}}$ distributed as a multivariate normal distribution with a mean of zero, and a variance-covariance matrix that must be symmetric $\left(\rho_{\mathrm{jk}}=\rho_{\mathrm{kj}}\right.$, for $\left.k=1,2, \ldots, 4\right)$ and have 1 s on its diagonal.

$y_{i j}$ is a binary response taking the value of 1 if the respondent thinks $j$ is a barrier; otherwise $y_{i j}$ equals zero. Thus, $y_{i j}$ is written as:

$$
Y_{i j}= \begin{cases}1 & \text { if respondent i choses item } j \text { is a barrier }\left(y_{i j}^{*}>0\right) \\ 0 & \text { otherwise }\end{cases}
$$

Then the joint log-likelihood function of four barriers $(j=1,2, \ldots 4)$ for a total number of $n$ observations is written as:

$$
L=\sum_{i=1}^{n} \log \Phi_{4}\left(\mu_{i}, \mathbf{\Omega}\right)
$$

where $\Phi_{4}$ follows multivariate normal distribution. The argument $\mu_{i}$ is:

$$
\mu_{i}=\left(K_{i 1} \beta_{1}^{\prime} X_{i 1}, K_{i 2} \beta_{2}^{\prime} X_{i 2}, \ldots, K_{i 4} \beta_{4}^{\prime} X_{i 4}\right)
$$

where $K_{i k}=2 y_{i k}-1$ for $k=1,2, \ldots 4$, and the $\boldsymbol{\Omega}$ is a matrix consisting of $\Omega_{\mathrm{jk}}$ elements which is written as: 


$$
\Omega_{j k}= \begin{cases}1 & \text { if } j=k \\ \Omega_{k j}=K_{i k} K_{i j} \rho_{j k} & \text { if } j \neq k\end{cases}
$$

According to Cappellari and Jenkins (2003), this log-likelihood function in equation (3) can be estimated by simulated maximum likelihood using STATA.

After estimating the coefficients, we calculated the marginal effects for each explanatory variable. The marginal effect for a continuous variable represents the probability of perceiving a barrier as an issue, given a one-unit change of the explanatory variable. For a dummy variabl the marginal effect represents the probability change of perceiving a barrier is an issue, given a move from the base to the dummy variable of interest. Particularly, we are interested in the marginal effects of each explanatory variable on the success probability, namely the probability of dependent variable $y_{i j}=1$.

Assuming all the independent variables are holding at their mean values, the marginal effect for a continuous explanatory variable $x_{i j}$ is calculated by:

$$
\text { marginal effect of } x_{i j}=\operatorname{Pr}\left(y_{i j}=1 \mid x_{i j}=x_{i j}+1\right)-\operatorname{Pr}\left(y_{i j}=1 \mid x_{i j}=x_{i j}\right)
$$

The marginal effect of a dummy variable $x_{i j}$ is calculated by:

$$
\text { marginal effect of } x_{i j}=\operatorname{Pr}\left(y_{i j}=1 \mid x_{i j}=1\right)-\operatorname{Pr}\left(y_{i j}=1 \mid x_{i j}=0\right)
$$

Further, in order to check the significance level $o x_{i j}$ f average marginal effect, we applied a bootstrapping method to calculate means and standard errors for the marginal effects. The average value of marginal effects for the buyer group and nonbuyer groups are presented in Tables 3 and 4.

\section{Endogeneity}

It is possible that there are some unoerved factors that affect consumers' perception of barrier $j$ that might be correlated with their expenditures on local food. Therefore, we use control functions to address the potential endogeneity of expenditure because they are straightforward to incorporate into consumer choice models. Following Petrin and Train (2010), we decompose the endogenous variable, expenditure $\exp _{i j}$, such that it is expressed as the sum of a linear combination of exogenous instruments $\boldsymbol{Z}_{i j}$ and an unobserved expenditure shock $\eta_{\mathrm{ij}}$ :

$$
\exp _{i j}=\theta_{j}^{\prime} \mathbf{Z}_{i j}+\eta_{i j}
$$

The endogeneity of expenditure on local food arises if $\eta_{\mathrm{ij}}$ and $\varepsilon_{\mathrm{ij}}$ are correlated. The control function approach handles the potential endogeneity problem by 
Table 3. Marginal Effects Associated with Barriers for Local Food Buyers Purchasing More Local Food

\begin{tabular}{|c|c|c|c|c|c|c|c|c|}
\hline Variables & Price & p-value & Quality & p-value & Availability & p-value & Labeling & p-value \\
\hline Female & 0.026 & 0.500 & -0.005 & 0.816 & -0.088 & 0.011 & 0.036 & 0.246 \\
\hline Age & -0.002 & 0.125 & -0.0004 & 0.623 & 0.0003 & 0.821 & -0.001 & 0.486 \\
\hline Income & -0.001 & 0.008 & -0.0003 & 0.175 & 0.001 & 0.049 & 0.000 & 0.807 \\
\hline Caucasian & 0.103 & 0.077 & -0.053 & 0.224 & -0.023 & 0.717 & 0.090 & 0.035 \\
\hline Some college & 0.061 & 0.290 & 0.003 & 0.935 & 0.001 & 0.986 & 0.036 & 0.494 \\
\hline Bachelor & 0.108 & 0.045 & -0.040 & 0.125 & -0.043 & 0.510 & 0.115 & 0.058 \\
\hline Master's or higher & 0.066 & 0.244 & -0.024 & 0.463 & -0.020 & 0.767 & 0.146 & 0.012 \\
\hline No. of children in household & 0.037 & 0.120 & 0.003 & 0.815 & 0.025 & 0.247 & -0.006 & 0.783 \\
\hline No. of adults in household & 0.030 & 0.226 & 0.002 & 0.874 & -0.003 & 0.890 & 0.008 & 0.687 \\
\hline Overweight & 0.047 & 0.286 & 0.028 & 0.247 & -0.033 & 0.383 & -0.008 & 0.820 \\
\hline Obese & 0.070 & 0.140 & 0.049 & 0.079 & -0.067 & 0.148 & -0.009 & 0.809 \\
\hline Food neophobia index & 0.032 & 0.076 & 0.009 & 0.462 & -0.003 & 0.854 & -0.007 & 0.619 \\
\hline Health-diet habit index & 0.029 & 0.206 & -0.008 & 0.565 & 0.062 & 0.006 & -0.009 & 0.672 \\
\hline Local expenditure & -0.262 & 0.282 & 0.109 & 0.631 & -0.058 & 0.864 & 0.034 & 0.868 \\
\hline Supermarket/Grocery & 0.110 & 0.151 & -0.050 & 0.376 & 0.145 & 0.077 & 0.003 & 0.967 \\
\hline Farmer's market & -0.021 & 0.616 & 0.012 & 0.591 & 0.165 & 0.0002 & -0.006 & 0.848 \\
\hline Roadside stand/CSA & -0.034 & 0.457 & -0.014 & 0.577 & 0.051 & 0.226 & -0.055 & 0.156 \\
\hline Warehouse clubs & 0.087 & 0.015 & 0.013 & 0.522 & 0.050 & 0.185 & -0.032 & 0.373 \\
\hline Ethnic and specialty health grocery store & -0.047 & 0.337 & 0.003 & 0.907 & 0.058 & 0.215 & 0.093 & 0.052 \\
\hline Discount grocery store & 0.145 & 0.002 & 0.019 & 0.493 & -0.016 & 0.784 & 0.022 & 0.647 \\
\hline Merchandiser & -0.027 & 0.573 & -0.004 & 0.880 & 0.079 & 0.094 & -0.011 & 0.789 \\
\hline
\end{tabular}




\section{Table 3. Continued}

\begin{tabular}{lcccccccc}
\hline Variables & Price & $\boldsymbol{p}$-value & Quality & $\boldsymbol{p}$-value & Availability & $\boldsymbol{p}$-value & Labeling & $\mathbf{p}$-value \\
\hline Other & -0.083 & 0.250 & -0.003 & 0.938 & 0.104 & 0.142 & -0.038 & 0.539 \\
Population density & -0.003 & 0.856 & -0.002 & 0.820 & -0.007 & 0.665 & -0.011 & 0.356 \\
Percent female (1\% increase) & -0.003 & 0.680 & 0.009 & 0.114 & 0.007 & 0.366 & -0.003 & 0.740 \\
Percent Caucasian (1\% increase) & -0.002 & 0.618 & 0.001 & 0.772 & 0.003 & 0.488 & -0.002 & 0.491 \\
Percent African American (1\% increase) & -0.004 & 0.336 & 0.0001 & 0.961 & -0.001 & 0.750 & -0.002 & 0.582 \\
Household income (2012) & 0.00002 & 0.964 & 0.0003 & 0.311 & $-\mathbf{0 . 0 0 1}$ & $\mathbf{0 . 0 8 7}$ & -0.0001 & 0.814 \\
Median age & -0.006 & 0.392 & -0.002 & 0.590 & 0.003 & 0.554 & -0.002 & 0.739 \\
No. of farmer's markets & 0.014 & 0.542 & 0.003 & 0.817 & 0.026 & 0.242 & 0.018 & 0.393 \\
\hline
\end{tabular}

Note: (a) We included the term to correct for endogeneity in the multivariate probit model, but do not report it in the marginal effects table. (b) Bold indicates significance at the 0.10 level or less. 
Table 4. Marginal Effects Associated with Barriers for Nonlocal Food Buyers Entering the Market for Local Food

\begin{tabular}{|c|c|c|c|c|c|c|c|c|}
\hline Variables & Price & p-value & Quality $^{\mathbf{a}}$ & p-value & Availability & p-value & Labeling & $p$-value \\
\hline Female & 0.136 & 0.228 & - & - & -0.061 & 0.591 & 0.060 & 0.466 \\
\hline Age & -0.001 & 0.782 & - & - & 0.001 & 0.724 & 0.003 & 0.337 \\
\hline Income & -0.001 & 0.452 & - & - & -0.0004 & 0.710 & 0.001 & 0.418 \\
\hline Caucasian & -0.014 & 0.929 & - & - & 0.012 & 0.943 & 0.159 & 0.012 \\
\hline Some college & 0.125 & 0.484 & - & - & 0.246 & 0.188 & 0.051 & 0.749 \\
\hline Bachelor & 0.053 & 0.731 & - & - & 0.281 & 0.114 & 0.168 & 0.323 \\
\hline Master's or higher & 0.234 & 0.140 & - & - & 0.323 & 0.098 & 0.346 & 0.134 \\
\hline No. of children in household & 0.008 & 0.900 & - & - & -0.021 & 0.666 & -0.006 & 0.887 \\
\hline No. of adults in household & -0.043 & 0.445 & - & - & 0.118 & 0.025 & 0.195 & 0.048 \\
\hline Overweight & 0.023 & 0.861 & - & - & -0.102 & 0.317 & 0.032 & 0.736 \\
\hline Obese & 0.130 & 0.390 & - & - & -0.158 & 0.080 & -0.071 & 0.443 \\
\hline Food neophobia index & -0.055 & 0.442 & - & - & -0.034 & 0.341 & -0.026 & 0.510 \\
\hline Health-diet habit index & -0.063 & 0.463 & - & - & 0.254 & 0.017 & 0.183 & 0.094 \\
\hline Local expenditure $^{\mathrm{b}}$ & - & - & - & - & - & - & - & - \\
\hline Supermarket/Grocery & 0.367 & 0.065 & - & - & -0.130 & 0.546 & -0.450 & 0.086 \\
\hline Farmer's market $^{\mathrm{b}}$ & - & - & - & - & - & - & - & - \\
\hline Roadside stand/CSA ${ }^{\mathrm{b}}$ & - & - & - & - & - & - & - & - \\
\hline Warehouse clubs & 0.163 & 0.286 & - & - & -0.070 & 0.550 & -0.134 & 0.102 \\
\hline Ethnic and specialty health grocery store & 0.169 & 0.396 & - & - & -0.118 & 0.415 & -0.104 & 0.330 \\
\hline Discount grocery store & 0.034 & 0.859 & - & - & 0.071 & 0.714 & -0.028 & 0.805 \\
\hline Merchandiser & 0.125 & 0.423 & - & - & 0.174 & 0.261 & 0.013 & 0.929 \\
\hline
\end{tabular}


Table 4. Continued

\begin{tabular}{lcccccccc}
\hline Variables & Price & $\boldsymbol{p}$-value & Quality $^{\mathbf{a}}$ & $\boldsymbol{p}$-value & Availability & $\boldsymbol{p}$-value & Labeling & $\boldsymbol{p}$-value \\
\hline Other & -0.325 & 0.186 & - & - & 0.088 & 0.741 & 0.118 & 0.652 \\
Population density & -0.070 & 0.272 & - & - & -0.030 & 0.507 & 0.036 & 0.392 \\
Percent female (1\% increase) & -0.017 & 0.689 & - & - & -0.029 & 0.262 & -0.012 & 0.651 \\
Percent Caucasian (1\% increase) & -0.019 & 0.217 & - & - & 0.017 & 0.236 & 0.008 & 0.402 \\
Percent African American (1\% increase) & -0.010 & 0.652 & - & - & $\mathbf{0 . 0 3 6}$ & $\mathbf{0 . 0 9 3}$ & -0.001 & 0.945 \\
Household income (2012) & 0.001 & 0.780 & - & - & 0.002 & 0.432 & -0.001 & 0.545 \\
Median age & -0.0003 & 0.990 & - & - & 0.028 & 0.266 & -0.006 & 0.747 \\
No. of farmer's markets & $-\mathbf{0 . 1 4 6}$ & $\mathbf{0 . 0 6 5}$ & - & - & 0.020 & 0.782 & 0.103 & 0.206 \\
\hline
\end{tabular}

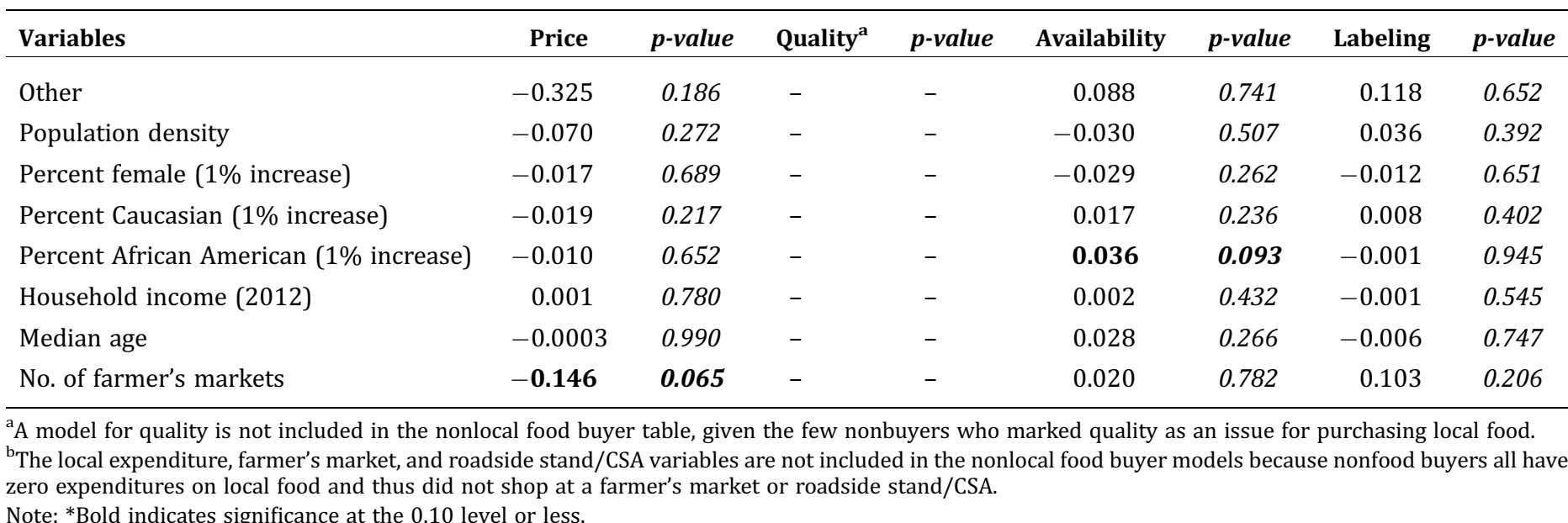

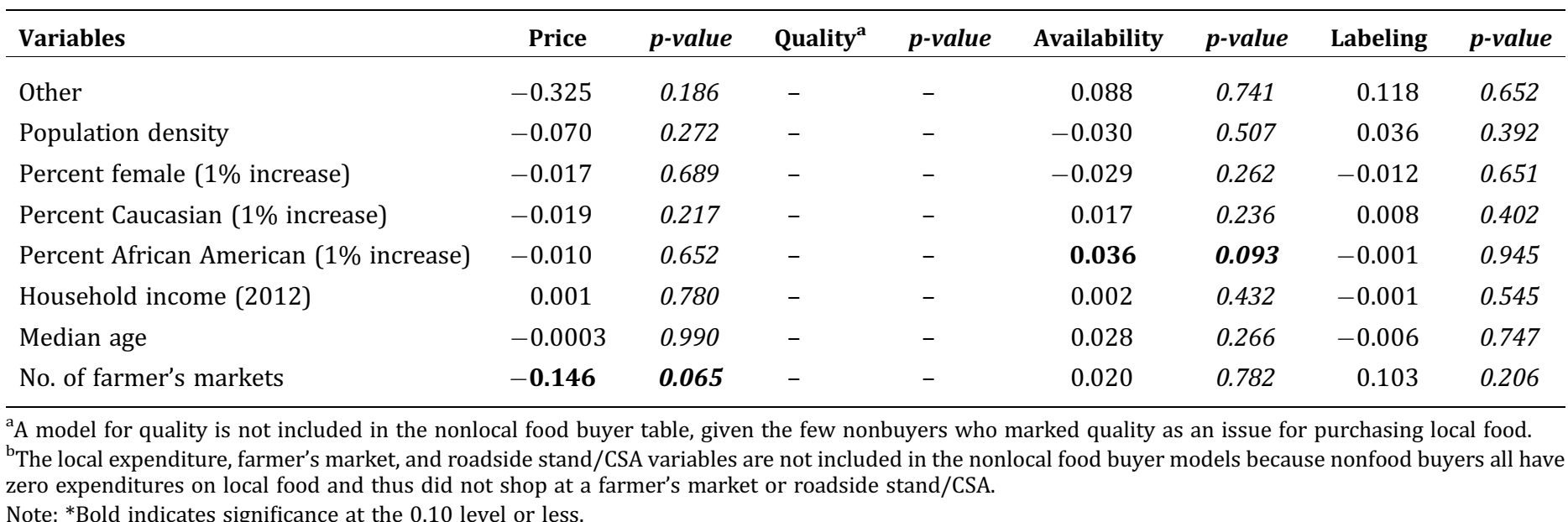

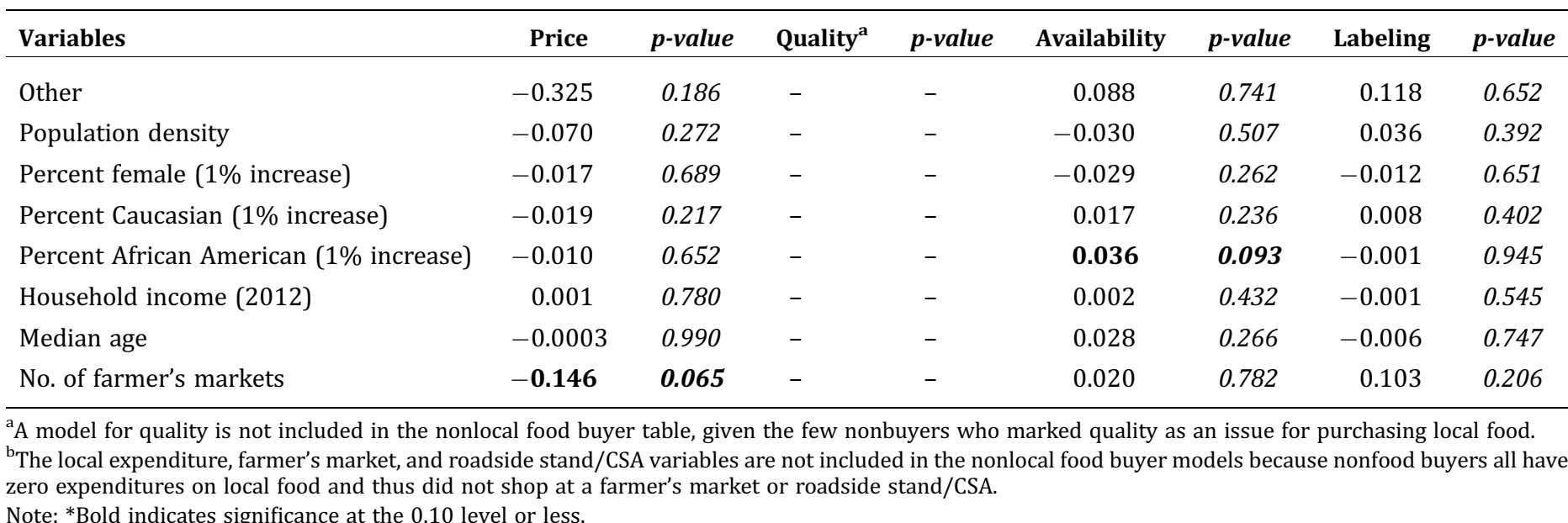

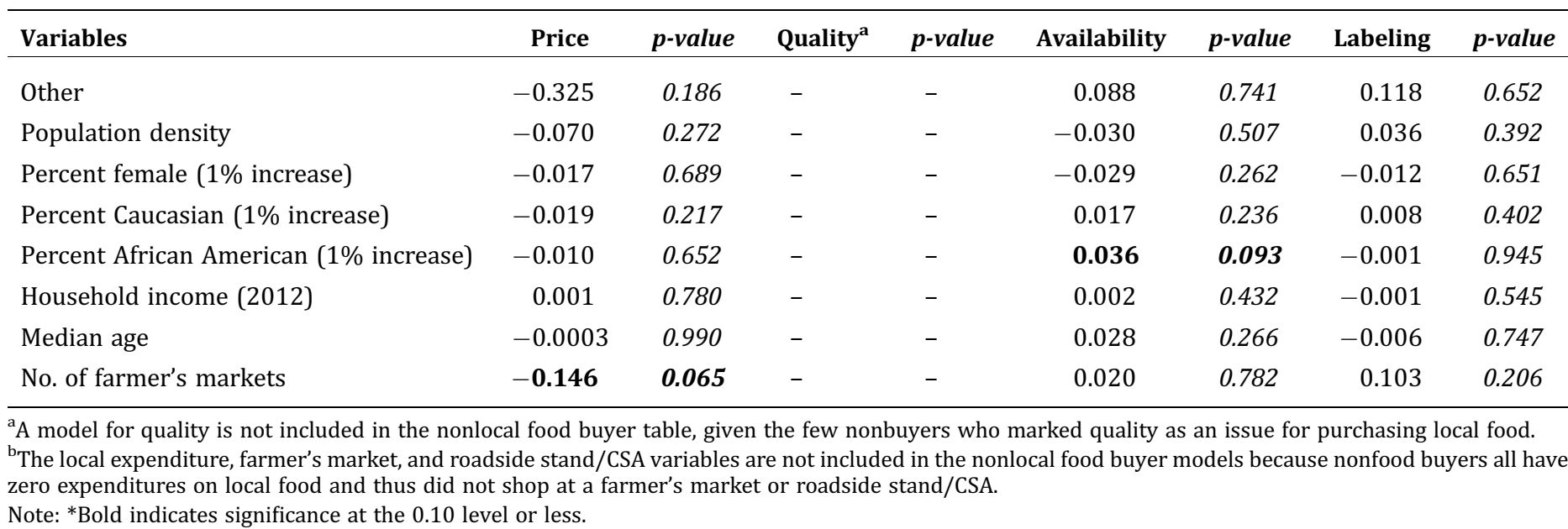

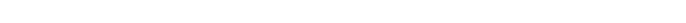


decomposing the error term $\varepsilon_{\mathrm{ij}}$ into two parts: the part that can be explained by a general function of $\eta_{\mathrm{ij}}$ (the unobserved factors that are known to consumers when they are making choices but unknown to econometricians), and the residual:

$$
\varepsilon_{i j}=F\left(\eta_{i j}, \lambda_{j}\right)+\widetilde{\varepsilon_{i j}}
$$

where $C F\left(\eta_{\mathrm{ij}}, \lambda_{\mathrm{j}}\right)$ denotes the control function with parameter $\lambda_{\mathrm{j}}$. The simplest approximation is to specify the function to be linear in $\eta_{\mathrm{ij}}$, namely $C F\left(\eta_{\mathrm{ij}}\right.$, $\left.\lambda_{\mathrm{j}}\right)=\lambda_{\mathrm{j}} \eta_{\mathrm{ij}}$. The choice model with the control function is then:

$$
y_{i j}^{*}=\beta_{j}^{\prime} \mathbf{X}_{i j}+\lambda_{j} \eta_{i j}+\widetilde{\varepsilon_{i j}}
$$

where error term is distributed as multivariate normal distribution with a mean of zero.

The instruments chosen for each barrier $j, \boldsymbol{Z}_{i j}$ are consumers' all other barriers. For example, in the equation that specifies price as a barrier, the instruments are all other barriers not including prices. The intuition is that one consumer's perception of other barriers, such as lack of products available and local foods not labeled, should be correlated to their total expenditures on local food. However, these perceptions of other barriers are less likely to affect their perception of higher prices.

\section{Results and Discussion}

\section{Buyers of Local Food}

Looking at Table 3 we can see the results for the multivariate probit model assessing the demographic, purchasing behavior, and health indicators impact on consumers already buying local foods and indicating a barrier to increasing their local food purchases. With respect to price as a barrier we see that lower income, and Caucasian consumers are more likely to indicate price as a barrier. Consumers were 0.1 percent less likely to say high prices are a barrier when average household income increases by $\$ 1,000$. Caucasian consumers were 10.3 percent more likely to say high prices are a barrier relative to other races. Consumers with a bachelor's degree have a 10.8 percent higher probability of being concerned about high prices relative to consumers with high school education or less. Consumers' dietary habits are another important factor influencing their perception of price as a barrier. A one-unit increase in the food neophobia score leads to a 3.2-percent higher probability of indicating high prices as a barrier. After controlling for endogeneity, we find that consumers' local food expenditure does not significantly influence any of the four barriers. However, shopping at 
warehouse clubs and discount stores increases the likelihood of perceiving price as a barrier to purchasing more local foods. A potential reason for this finding is that these retailers tend to have lower prices and seek lower cost options which are not typical of local foods.

With respect to quality as a barrier, we see that only the obese factor has a significant impact. A potential reason for this finding is that quality is not a major issue for local food barriers in purchasing local food, which is consistent with the result presented in Table 2 that only 11 percent of buyers are concerned about quality problems. As for obese people, they are 4.9 percent more likely to be concerned about the quality problem.

Now focusing on the availability barrier, females were less likely to perceive this as a barrier to increased purchasing. Females usually are primary shoppers for a household, and they spend more time grocery shopping than men, so they are potentially more familiar with local food placement in the market. Interestingly, consumers with one additional unit in their healthy diet score are 6.2 percent more likely to indicate that local food availability is a barrier. Thus, increasing local food availability is important for healthier consumers. As annual household income increases by $\$ 1,000$, consumers are 0.1 percent more likely to indicate availability is an issue. Consumers with higher income are typically faced with greater time constraints and thus are interested in either finding a greater variety of local foods or easier access. However, in ZIP codes with higher income there is also less concern about availability, as these are the communities where retailers are able to get a premium for local foods and are more likely to focus supply. These results provide interesting insight into to supply constraints: to increase purchasing of local foods, one must address availability issues for high-income consumers while also increasing the local food accessibility in lower-income communities.

Shopping locations are also important factors that affect consumers' perception of availability as a barrier. Consumers who shop at a supermarket are 14.5 percent more likely to find availability is a barrier to increasing local food purchases. Considering that the majority of food shopping occurs at supermarkets, it is important to increase the local food supply in these locations to increase overall local food consumption. One potential challenge, however, is that with chain supermarkets, which procure fresh foods for a larger distribution of stores, distribution that may not be possible for a local producer. Interestingly, shopping at a farmer's market also increases the likelihood of identifying availability as a barrier. From a policy perspective, the finding that consumers who shop at a farmer's market indicate the lack of available products as a barrier is enlightening; this suggests that consumers may feel constrained by the lack of variety of products available at these locations. To further support this, one would expect that as the number of farmer's markets increase in a ZIP code, consumers would be less concerned about availability. However, our results indicate there is no statistically significant impact. Based on these two findings, the policy of increasing access or the number of farmer's markets may not make a large 
difference in increasing local food consumption. Identifying the specific products consumers want is a more important strategy to increase local food purchasing than creating additional venues for existing products.

Consumers who value local food rely on labeling to identity local goods; however, as noted in Table 2, 25 percent of buyers indicate lack of labeling as an issue in purchasing more local food. According to the results in Table 3, Caucasian and higher-educated consumers were more likely to cite lack of labeling as an issue. For instance, Caucasian consumers were 9 percent more likely to indicate labeling as an issue overall, while having a bachelor's degree resulted in an 11.5-percent increase, and having a master's degree or higher resulted in a 14.6-percent increase. Furthermore, consumers shopping at ethnic and specialty health stores were 9.3 percent more likely to cite labeling as an issue. This highlights a concern that certain consumers may not be aware of products' origins and thus do not know if a given product is locally produced or not. The State of Connecticut Department of Agriculture has recently started to address this issue by making available point-ofpurchase material that not only indicates if a product is Connecticut grown but also gives the farm name and town where it was grown.

\section{Nonbuyers of Local Food}

Some consumers either do not know they purchase local or do not purchase local food. In either case, there is a need to understand who these consumers are to target them to become local food buyers. We have a relatively smaller sample size of nonbuyers, with 167 observations. While we attempted to estimate the same four-equation MVP, it was necessary to drop quality due to the few nonbuyer respondents that indicated this as a barrier. Therefore, we analyzed three barriers (price, availability, and labeling) for the nonbuyer group. We also dropped the variables farmer's market and roadside stand/ CSA because these are zero for all nonbuyers.

For nonbuyers, there are fewer factors influencing price as a barrier relative to availability and labeling. Nonbuyers who shop at supermarkets/grocery stores are more likely to indicate price as a barrier. Additionally, nonbuyers in ZIP codes where there are more farmer's markets are less likely view price as a barrier to purchasing local. One reason for this is that nonbuyers may perceive communities with farmer's markets as having more competitive prices for local foods, yet when shopping in supermarkets they see higher prices and choose not to buy local.

Looking at the results for availability, the perceived lack of local food availability is an issue for higher-educated nonbuyers. For instance, nonbuyers with a master's or higher degree was 32.3 percent more likely to perceive availability problems. Furthermore, for each additional adult in the household, a consumer was 11.8 percent more likely to be concerned about availability of local foods. From a health aspect, obese nonbuyers have a lower likelihood of perceiving availability as a barrier, while consumers 
scoring higher on the healthy diet index are more likely to be concerned with availability. This is consistent with expectations where obese nonbuyers are generally not interested in local foods that are perceived to be healthier alternatives while consumers who are interested in healthy eating feel constrained by not being able to find the local foods they want.

Examining the labeling barrier, we see that consumers shopping at supermarkets/grocery stores are less likely to indicate lack of labeling as a barrier. However, Caucasian consumers and consumers with a healthier diet are more likely to perceive labeling as an issue. With each additional adult in the household, there was a 19.5-percent higher probability for a participant in the nonbuyer group to perceive local products not being labeled as a barrier.

Comparing the perceptions of buyer and nonbuyer groups, we find that a higher health-diet habit index always leads to a higher likelihood of perceiving the lack of local food availability. Thus, increasing local food supplies is important for people with healthy dietary habits. Alternatively, Caucasian buyers and nonbuyers are more likely to be concerned about lack of labeling. Therefore, labeling local foods clearly is an important strategy to increase local food purchasing among Caucasians.

\section{Conclusions}

Many states and communities are striving to increase local food production and consumption. To accomplish this, policymakers and value chain members generally implement one-size-fits-all strategies. However, our results indicate that a one-size-fits-all approach may not have the desired effects, as buyers and nonbuyers of local food have differing barriers to purchasing more local food or entering the market for local food. Availability concerns are the major barriers for the buyers group, while high prices are the major barrier for the nonbuyers group. In addition, although we find consumers with healthier dietary habits in both groups are more likely to be concerned about lack of available local food, the other characteristics have differing impacts on their perception of barriers for consumers in these two groups. For example, consumers' characteristics, such as income, race, and education, significantly influence consumers' perceptions of high prices as a barrier in the buyers group, but none of these characteristics indicate concern for high prices as a barrier in the nonbuyers group. Ultimately, strategies focusing on increasing availability will affect current buyers more than nonbuyers.

Nonbuyers indicating that price is a barrier, in conjunction with the buyer results indicating that price is a barrier, suggest that retailers (in particular supermarket/grocery stores) charging premiums for local foods may be limiting increases in sales. As has been noted in numerous studies, consumers are willing to pay price premiums for local foods (Gracia, Barreiro-Hurlé, and López-Galán, 2014). However, our results indicate that premiums over nonlocal food are a barrier to nonbuyers who shop in supermarket or grocery stores and are concerns of specific buyers. This 
presents a conundrum to retailers and policymakers as retailers strive for increased profits, which premiums on local foods might deliver; however, from a social justice/sustainability perspective, consuming locally sourced foods is not about profits but rather about helping the local community/ environment.

Further, demographics, purchasing behaviors, health, and community characteristics play a role in a consumers' barriers to purchasing more local food. Notably for local food buyers, local food has been described by popular media outlets (e.g., cnn.com) as a possible solution to the obesity epidemic within the United States (Pollan 2006; Gustafson 2010; Nordahl 2013). However, our results indicate that obese consumers perceive quality as an issue to purchasing local food. We also find that buyers shopping at farmer's markets are more likely to perceive local food availability as a barrier, which indicate that consumers may look for specific products when shopping at these markets. Therefore, policies focusing on expanding the variety of supply of local foods becomes more important than increasing the number of retailers for local food.

The ability for policymakers to successfully increase the purchasing of local foods requires a better understanding of the current limitations consumers face in their present purchasing habits. We have identified a number of barriers that exist for increasing local food consumption or entering the market for local foods. Different types of consumers have different reasons, and thus it is important for marketing strategies to be targeted appropriately. It is also worth noting that 10 percent of buyers in our survey and 16 percent of nonbuyers in our survey are concerned about issues other than price, quality, availability, and labeling. Further research is recommended to identify these additional barriers.

\section{References}

Aurier, P., and V. Mejía. 2014. "Multivariate Logit and Probit Models for Simultaneous Purchases: Presentation, Uses, Appeal and Limitations." Recherche et Applications en Marketing (English Edition) 29(2): 75-94.

Bethlehem, J. 2010. "Selection Bias in Web Surveys." International Statistical Review 78(2): 161-188.

Brown, C. 2003. “Consumers' Preferences for Locally Produced Food: A Study in Southeast Missouri." American Journal of Alternative Agriculture 18(4): 213-224.

Cappellari, L., and S.P. Jenkins. 2003. "Multivariate Probit Regression Using Simulated Maximum Likelihood." The Stata Journal 3(3): 278-294.

Chambers, S., A. Lobb, L. Butler, K. Harvey, and W.B. Traill. 2007. "Local, National and Imported Foods: A Qualitative Study." Appetite 49(1): 208-213.

Cobanoglu, C., B. Warde, and P. Moreo. 2001. "A Comparison of Mail, Fax, and Web-based Survey Methods." International Journal of Market Research 43(4): 441-452.

Conner, D., K. Colasanti, R.B. Ross, and S.B. Smalley. 2010. "Locally Grown Foods and Farmers Markets: Consumer Attitudes and Behaviors." Sustainability 2(3): 742-756.

Darby, K., M.T. Batte, S. Ernst, and B. Roe. 2008. "Decomposing Local: A Conjoint Analysis of Locally Produced Foods." American Journal of Agricultural Economics 90(2): 476-486. 
Dillman, D., J. Smyth, and L. Christian. 2009. Internet, Mail, and Mixed-model Surveys: The Tailored Design Method. Hoboken, NJ: John Wiley \& Sons, Inc.

Durham, C.A., R.P. King, and C.A. Roheim. 2009. “Consumer Definitions of 'Locally Grown' for Fresh Fruits and Vegetables." Journal of Food Distribution Research 40(1): 56-62.

Edwards, Y.D., and G.M. Allenby. 2003. "Multivariate Analysis of Multiple Response Data." Journal of Marketing Research 40(3): 321-334.

Fernández-Ferrín, P., Bande, B., Calvo-Turrientes, A., and Galán-Ladero, M. M. 2016. "The Choice of Local Food Products by Young Consumers: The Importance of Public and Private Attributes." Agribusiness: An International Journal (32)2.

Gracia, A., J. Barreiro-Hurlé, and B. Lòpez-Galán. 2014. "Are Local and Organic Claims Complements or Substitutes? A Consumer Preferences Study for Eggs." Journal of Agricultural Economics 65(1): 49-67.

Governor's Council for Agricultural Development. 2011. Available at http://www.ct.gov/ doag/cwp/view.asp?a=3595\&q=423842 (accessed June, 3, 2015)

Gustafson, E. 2010. "Solving the World's Hunger and Obesity Crisis Together." Available at http://www.cnn.com/2010/OPINION/08/10/gustafson.hunger.obesity/ (Accessed June 4, 2015).

Hand, M.S., and S. Martinez. 2010. "Just What Does Local Mean?" Choices 25(1): 13-18.

Hardesty, S.D. 2008. "The Growing Role of Local Food Markets." American Journal of Agricultural Economics 90(5): 1289-1295.

Jekanowski, M.D., D.R. Williams, and W.A. Schiek. 2000. “Consumers' Willingness to Purchase Locally Produced Agricultural Products: An Analysis of an Indiana Survey." Agricultural and Resource Economics Review 29(1): 43-53.

Low, S.A., and S. Vogel. 2011. Direct and Intermediated Marketing of Local Foods in the United States. Economic Research Report 128. Economic Research Service, U.S. Department of Agriculture: Washington, DC.

Martinez, S., M. Hand, M. Da Pra, S. Pollack, K. Ralston, T. Smith, S. Vogel, S. Clark, L. Lohr, S. Low, and C. Newman. 2010. "Local Food Systems: Concepts, Impacts, and Issues." Available at http://www.ers.usda.gov/media/122868/err97_1_.pdf (Accessed May 13, 2014).

McCullough, D. 1998. “Web-based Market Research: The Dawning of a New Age.” Direct Marketing 61: 36-38.

Nordahl, D. 2013. "Solving Obesity Crisis: Strawberries in Parking Lots.” Available at http:// www.cnn.com/2013/07/12/world/solving-obesity-crisis-strawberries/ (Accessed June 4, 2015).

Onken, K.A., and J.C. Bernard. 2010. "Catching the 'Local' Bug: A Look at State Agricultural Marketing Programs." Choices 25(1): 1-7.

Onozaka, Y., G. Nurse, and D.T. McFadden. 2010. "Local Food Consumers: How Motivations and Perceptions Translate to Buying Behavior." Choices 25(1): 1-6.

Petrin, A., and K. Train. 2010. "A Control Function Approach to Endogeneity in Consumer Choice models." Journal of Marketing Research 47(1): 3-13.

Pliner, P., and K. Hobden. 1992. "Development of a Scale to Measure the Trait of Food Neophobia in Humans." Appetite 19(2): 105-120.

Pollan, M. 2006. The Omnivore's Dilemma: A Natural History of Four Meals. New York, NY: The Penguin Group.

Rabinowitz, A.N., and L. Riva. 2015. "Estimates of Consumption of Locally-Grown Agricultural Products in Connecticut." Invited Presentation before the Connecticut Governor's Council for Agricultural Development.

Seyfang, G. 2006. "Ecological Citizenship and Sustainable Consumption: Examining Local Organic Food Networks." Journal of Rural Studies 22(4): 383-395.

Sharp, J.S., J.K. Clark, G.A. Davis, M.B. Smith, and J.S. McCutcheon. 2011. “Adapting Community and Economic Development Tools to the Study of Local Foods: The Case of Knox County, Ohio." Journal of Extension 49(2): 1-12. 
Sims, R. 2009. "Food, Place and Authenticity: Local Food and the Sustainable Tourism Experience." Journal of Sustainable Tourism 17(3): 321-336.

Teratanavat, R., and N.H. Hooker. 2006. "Consumer Valuations and Preference Heterogeneity for a Novel Functional Food." Journal of Food Science 71(7): S533-S541.

Verbeke, W., and G.P. López. 2005. "Ethnic Food Attitudes and Behaviour Among Belgians and Hispanics Living in Belgium." British Food Journal 107(11): 823-840.

Vermeir, I., and W. Verbeke. 2006. "Sustainable Food Consumption: Exploring the Consumer 'Attitude-behavioral Intention' Gap." Journal of Agricultural and Environmental Ethics 19 (2): 169-194.

Warner, T., R. Lopez, A. Rabinowitz, and B. Campbell. 2012. Estimates of Consumption of Locally-Grown Agricultural Products in Connecticut. (No. 10). University of Connecticut, Department of Agricultural and Resource Economics, Charles J. Zwick Center for Food and Resource Policy. Available at http://purl.umn.edu/153402 (Accessed June, 3, 2015). 